\title{
Plant influences on endophyte expression
}

\author{
C.P. WEST \\ University of Arkansas, 1366 W. Altheimer Dr., Fayetteville, AR 72704 USA
}

cwest@uark.edu

\begin{abstract}
Neotyphodium endophytes in the pooid grasses perennial ryegrass and tall fescue (Lolium spp.) are important ecologically and agriculturally by virtue of their ability to produce several alkaloids and their effects on host growth and responses to biotic and abiotic stresses. Such responses can be positive, neutral, or negative, and depend on the interaction of host genetics $\mathrm{x}$ endophyte genetics $\mathrm{x}$ environment (and management), which is complex and difficult to predict. Understanding the interactions is key to elucidating the ecological role of endophytes in natural and impacted ecosystems and to optimally select plant and endophyte combinations that support profitable livestock production with stable plant populations. High phenotypic variability among individual plants in an endophyte-infected population can promote population fitness across a wide range of stressful environments. Strong interactions between environmental conditions and host-endophyte combination reveal the importance of testing new grass-endophyte associations in the range of environments targeted for eventual use to determine stability of the desired traits. Care must also be taken when creating new symbiota that an important fitness trait is not lost by selecting endophytes that lack a particular alkaloid. Genetic variations within perennial ryegrass and tall fescue provide opportunities for plant breeders to perform further selections with novel symbiota to exploit host control over growth and physiology and thus overcome some of performance loss. This paper reviews the challenges of understanding grass-endophyte interactions, with particular attention to strategies of improving the performance of novel symbiota for agricultural purposes.
\end{abstract}

Keywords: Lolium, Festuca, Neotyphodium, plant-endophyte interactions, symbiosis

\section{Introduction}

Symbiota involving host grasses of the Pooidae subfamily and fungal endophytes of the genus Neotyphodium (and Epichoë for the sexual stage) have attracted much research attention since the late 1970s from the perspective of agriculture, ecology, and more recently molecular biology. Perennial ryegrass (Lolium perenne L.) and tall fescue [L. arundinaceum (Schreb.) Darbysh.=syn. Festuca arundinacea Schreb.] are the grasses most studied because of widespread livestock toxicoses caused by alkaloids produced by their respective endophytes $N$. lolii and $N$. coenophialum. The biotic partners are widely considered mutualists, as evidenced by myriad reports of endophyte enhancement of host resistances to abiotic and biotic stresses (Clay \& Schardl 2002; Malinowski \& Belesky 2006). In natural populations of grasses with related endophytes, the benefits of the endophytes are less frequent and intense, or may actually be neutral or negative (Faeth et al. 2004; Saikonnen et al. 2006).

The phenotype of the association varies with host genotype, endophyte genotype, environment (including management), and all possible interactions thereof. Three-component interactions are often unpredictable and difficult to comprehend. Such interactions are of great interest from a basic level to better understand ecological phenomena in wild and managed plant communities involving herbivory, and from an applied level as efforts intensify to create new symbiota with endophytes selected for conferring fitness benefits to the host and for the lack of livestock toxins. Ideotype symbiota offer promise to lower the cost and increase profitability of animal production; however, questions remain as to what fitness traits may be lost by selecting so-called nontoxic endophytes. This paper reviews the knowledge gained from studies of plant-endophyte interactions with emphasis on whole plant responses.

\section{Nature of the Interactions}

There are three general approaches to studying genetic interactions between plant and endophyte; 1) confounding or possible confounding of plant genotype with endophyte genotype (syn. = haplotype, strain, biotype); 2) constant plant genotype or cultivar with different endophyte genotypes; and 3) different plant genotypes or cultivars with a constant endophyte genotype. Approach 1 typified the early studies on grassendophyte interactions (e.g. Belesky et al. 1989). This involved the propagation of several random clones (putatively genetically different because of the outcrossing nature of tall fescue and perennial ryegrass), generation of endophyte-free (E-) versions of those clones by fungicide treatment, then comparing back to the infected $(\mathrm{E}+)$ clone for plant growth, drought tolerance, pest resistance, competitiveness, etc. If the clones came from the same cultivar, they may have contained the same strain of endophyte because of its asexual mode reproduction, maternally vertical transmission across generations, and the relative purity of a closed population; however, the genotypes of the endophytes in such studies were rarely, if ever, confirmed. The value of such studies was that they exposed the huge interplant variation that can occur, with and without their native endophytes, and the complexity of plant growth forms that contribute to population survival and productivity in widely variable environments.

Approaches 2 and 3 involve purposeful inoculations or controlled backcrossing to generate a common host population or cultivar with more than one endophyte strain, or generate more than one host population with a common endophyte strain. The value of these approaches is that they isolate the source of phenotypic variation to one or the other organism, thereby allowing more accurate elucidation of physiological mechanisms involved in, for example, pest deterrence. Such approaches also facilitate the identification of endophytes which most stably express beneficial traits across host genotypes and those symbiota which are most compatible.

\section{Endophyte Expression through Plant Responses}

\section{Growth and abiotic stresses}

The discoveries by Latch et al. (1985) and Clay (1987) of higher biomass yields in $\mathrm{E}+$ than in $\mathrm{E}$ - perennial ryegrass and tall fescue in controlled conditions (thus avoiding confounding effects of herbivory) have encouraged other workers to study the consistency of such responses across plant genotypes. West (1994) reviewed numerous cases in which individual plant genotypes were inconsistent as to their growth response to endophyte presence. He generalised that tall fescue growth, 
tillering, and seed production tended to be greater with endophyte, although there were many cases of individual genotypes showing neutral or negative endophyte effects (e.g. Cheplick 1998). Hill et al. (1990) reported tall fescue genotype $\mathrm{x}$ infection-status interactions for tillering, crown and shoot weight, nonstructural carbohydrate content, and specific leaf weight. They speculated that the endophyte enhances different arrays of fitness traits among individual plants, thereby lending phenotypic heterogeneity to the population and increased stability as environmental conditions and stresses fluctuate. Belesky \& Fedders (1996) demonstrated opposite effects of endophyte presence on growth, carbohydrate, and nitrogen use of two tall fescue genotypes, the extent of which depended on whether the plants were defoliated.

In perennial ryegrass, Lewis (2004) found minor host genotype $\mathrm{x}$ endophyte interactions for growth; whereas Hesse et al. (2004) found substantial interactions. In the latter study, whether the endophyte benefited or reduced plant performance often depended on the original environment of collection, i.e. flooding and drought-prone sites produced plants whose endophytes were likely to depress herbage and seed yield. The authors suggested that natural selection forces in the original habitat created symbiota whose physiological interactions were optimised for survival in those environments (Hesse et al. 2003, 2004).

Cheplick (1998) likewise reported significant host-genotype effects on plant response to endophyte presence in perennial ryegrass cv. Yorktown III for regrowth after clipping, which also interacted with nutrient supply level. Further studies on individual genotypes from the same population (Cheplick et al. 2000) revealed wide variation among grass genotypes in shoot recovery from drought, but no endophyte effects on tiller number and live leaf area. However, endophyte status did interact with host genotype and water stress level in allocation of dry weight to tiller bases, an index of storage reserves. In this interaction, tiller base storage was reduced by drought stress in E+ but not in Eplants. The authors concluded that endophytes had little overall influence on regrowth. Further investigation of this population revealed significant host $\mathrm{x}$ endophyte interactions for recovery after clipping (Cheplick \& Cho 2003) and after drought stress (Cheplick 2004). Based on nonstructural carbohydrate analysis, they found no evidence of a metabolic cost to the host of harbouring the endophyte (Cheplick \& Cho 2003), although growth analysis sometimes suggested this phenomenon (Cheplick 2004). They concluded that in perennial ryegrass, as regards growth alone (in the absence of pest herbivory), endophyte mutualism is not obligate and fitness is host specific for particular environments rather than driven by endophyte symbiosis.

Gas exchange is also affected by host genotype $\mathrm{x}$ infection status. Marks \& Clay (1996) reported that photosynthesis rate in 13 tall fescue genotypes were positively, negatively, or not affected by endophyte status. Richardson et al. (1993) reported positive and neutral effects of endophyte presence on photosynthesis and stomatal conductance in two tall fescue genotypes, depending on severity of water deficit. Likewise, endophyte infection can have positive or negative effects on phosphorus (P) uptake in P-deficient soil (Malinowski \& Belesky 1999) and inconsistent effects on host drought survival (Buck et al. 1997). These results agree with the conclusion by Belesky \& Fedders (1996) that each host-endophyte combination has a unique phenotypic expression profile with respect to management and environmental stimuli, precluding the ability to generalise about endophyte effects on host plants based on observations of one host genotype.

The above cases involved comparisons of genotypes whose endophyte genetic identity was knowingly confounded with host genotype (e.g. Buck et al. 1997) or were not known or controlled, thereby limiting conclusions about direct genome effects (Approach 1). Studies using Approaches 2 and 3, in which host or endophyte genetics are controlled, have been aimed mainly at testing responses of the symbiota to endophytes selected for lack of livestock toxins in order to test for increased plant fitness or compatibility. These approaches attempt to test genotypic effects at the population level (e.g. endophyte strain 1 vs. strain 2 in cultivar A) instead of at the individual plant level. This occurs because it is most practical to artificially inoculate populations of very young seedlings and then reconstitute the cultivar, but impractical or impossible to artificially inoculating individuals of a common plant clone with several different endophytes. Therefore, a high degree of phenotypic heterogeneity within the tests populations is inescapable for heterozygous grasses like tall fescue and perennial ryegrass.

Eerens et al. (1998) tested perennial ryegrass cv. Grasslands Nui containing no endophyte, its natural wild-type endophyte, or novel strain AR6 (lacking the tremorgenic alkaloid lolitrem B) for growth and drought tolerance. Both endophytes reduced plant yield, with the novel endophyte causing less reduction. The authors warned that replacing a wild type endophyte with a novel endophyte via artificial inoculation could cause some genetic drift in the resultant population because the novel endophyte may "select" certain individuals among the host genotypes owing to differential compatibility. While possible, such drift is unlikely to be significant if sufficiently large numbers of seedlings are inoculated, and then are backcrossed to the original population to restore a similar genetic make-up (West et al. 1998).

Assuero et al. (2000) invoked Approaches 2 and 3 by forming combinations of two tall fescue cultivars x 2 endophyte strains (an ergopeptine-producing isolate from 'Kentucky-31' and the ergopeptine-lacking isolate AR501) and grew them in pots at four levels of water deficit. Both endophytes reduced leaf senescence relative to E- controls, with AR501 giving higher gross and net growth rates than the KY-31 isolate, suggesting a direct effect of strain on host growth and senescence patterns. Endophyte presence did interact with host in that infection by both endophytes reduced tiller number in 'Maris Kasba' but not in 'El Palenque.' Also, the KY-31 isolate tended to stimulate photosynthesis of Maris Kasba, whereas AR501 tended to stimulate photosynthesis in El Palenque, relative to E- controls. These results indicate effects of endophyte strain for a given host as well as effects of host for a given endophyte in growth, gas exchange and water relations, although in different directions. Therefore, similarly to earlier studies in which endophyte genetics was uncontrolled or confounded with host genetics, the better controlled study of Assuero et al. (2000) showed all kinds of inconsistent interactions. The authors appropriately concluded that because of the uniqueness of cultivar $\mathrm{x}$ endophyte responses, prediction of tall fescue field performance from controlled pots studies is impossible, thus necessitating field performance of candidate endophyte strains in their likely target cultivars.

\section{Responses to biotic stresses}

Neotyphodium endophytes impart host resistance or deterrence to a wide range of insects, some nematodes, and at least one fungal pathogen (West \& Gwinn 1993). The most recent thorough review of this topic was by Popay \& Bonos (2005). Host protection against pests and drought tolerance are the two major fitness traits sought in selections of novel endophytes (West et al. 1998). Indeed, it was the discovery of $N$. lolii strain AR1 and its successful incorporation into perennial ryegrass cv. Grasslands 
Nui that demonstrated the feasibility of selecting against a livestock toxin (lolitrem B) and for an insect toxin (peramine) as a means of averting ryegrass staggers in livestock while preserving plant persistence in New Zealand (Latch 1989). This strategy has served as a successful model for resolving fescue toxicosis (selecting against ergot alkaloids in N. coenophialum) while retaining tall fescue persistence (Bouton et al. 2002). Even though $N$. coenophialum deters aphids (Homoptera: Aphidiae; Eichenseer \& Dahlman 1992) and to a lesser degree fall armyworm (Spodopter frugiperda; Bultman and Conard 1998) in tall fescue, insect resistance is not the fitness trait of principal interest because insect herbivory is not an acute threat to tall fescue stand persistence in the U.S. (West et al. 1998). Rather, the fitness criterion for novel endophytes in tall fescue is tolerance to the summer abiotic stress complex, primarily drought and heat, with which no alkaloid profiles have been associated.

Argentine stem weevil (ASW, Listronotus bonariensis) damage is dramatically reduced by inoculating perennial ryegrass with peramine-producing endophytes (Popay et al. 1995); however, ASW resistance can vary among Lolium plant types even when all their respective endophytes produce peramine, suggesting other plant and endophyte-mediated factors at play. Popay et al. (2003) compared Lolium cultivars comprising diploid and tetraploid types and various degrees of hybrids between annual and perennial ryegrasses for extent of ASW resistance, all of which were in symbiosis with endophytes producing peramine and ergovaline. One cultivar, the tetraploid hybrid 'Greenstone,' did not produce lolitrem B. Hybrids and tetraploids incurred more damage than the perennials and diploids, a trend that was associated with lower leaf-lamina peramine concentrations in the former group. Greenstone always contained less the $15 \mathrm{mg} / \mathrm{kg}$ of peramine, considered the minimum threshold for inducing strong feeding resistance. The authors proposed that ASW deterrence was conferred primarily through the associations' control over peramine concentration and location in the leaf, but that other factors, such as lolitrem B presence (an endophyte genetic trait) and fibre and silica contents (plant genetic traits) may have contributed to the expression of ASW damage. Even though this research did not involve controlled inoculations of common endophyte strains across the host genotypes tested, it nonetheless exposed possible subtle and interacting roles of host traits, such as control of peramine translocation and insect attractiveness factors, on a critical biotic stressor for determining population sustainability. Such interactions likely exist for all stressors of interest, such as drought, livestock grazing, and nemotode feeding.

An intriguing story is emerging from recent research in New Zealand on root aphid (Aploneura lentisci), which illustrates the difficulty of selecting endophytes that confer wide-spectrum pest resistance. While investigating damage to E- perennial ryegrass cv. Grasslands Nui stands by pasture mealybug (Balanococcus poae), the authors also discovered infestations of root aphid (Pennell et al. 2005). Besides E- populations, the same cultivar contained associations with its wild-type endophyte (producer of lolitrem B, ergovaline, and peramine), strain AR1 (producer of peramine and known to deter ASW), and strain AR37 (producer of none of the alkaloids commonly found in wild-type but contains epoxy-janthitrems (Tapper \& Lane 2004) and also deters ASW). While all three endophytes imparted resistance to mealybug relative to E- plants, root aphid numbers were low in E- and in all associations except that containing strain AR1, which allowed high root aphid numbers. Thus, AR1 enhanced host susceptibility to root aphid relative to no endophyte.

Popay \& Easton (2006) aimed to determine whether host resistance to root aphid was a heritable trait thus allowing selection of genotypes with greater resistance to root aphid when containing strain AR1. They analysed aphid numbers on 20 individual plants that were either E-, infected with AR1, or infected with the wild-type. Plant genotype affected aphid numbers in the E- group to a modest degree, but variability increased substantially with infection with AR1, indicating a strong host genotype $\mathrm{x}$ endophyte interaction for susceptibility to root aphid. Half-sib families showed significant variation in root aphid numbers. Three out of 16 families showed low aphid numbers and relatively high plant yield, thereby providing the basis for breeding a perennial ryegrass population that optimises host genetic combinations with an endophyte strain that provides other beneficial traits, such as ASW and mealybug resistance.

There is concern that selecting endophytes and host grasses for desirable traits independently and then combining them to mitigate agricultural limitations can result in symbiota that have reduced robustness relative to their wild sources (Fletcher et al. 2006). Artificial symbiota do not undergo the same intensity and duration of selection for mutual compatibility and fitness endured by natural populations, and therefore may fall short in such traits as transmission rates via seed, wide-spectrum pest resistance, and the myriad of hormonal and metabolic conditions that favor plant growth and persistence under unfavorable environmental conditions. Examples in tall fescue include reduced host resistance to lesion nematode (Pratylenchus scribneri, Timper et al. 2005) and bird-cherry oat aphid (Hunt \& Newman 2005) when the wild-type endophyte was replaced with strain AR542, a strain without ergovaline. Fletcher et al. (2006) recommended inoculating genetically diverse grass germplasm with an endophyte(s) selected for nontoxicity to livestock, then breed within this pool for robust and stable fitness traits for the intended range of environmental conditions.

\section{Alkaloid Profiles and Host Control}

Alkaloid profiles have been widely studied as indicators of hostendophyte interactions because of their ecological and agricultural significance and because they afford a distinctly measurable metabolite resulting from the symbiosis. The complexity of natural ecosystems with regard to grass-endophyte effects on herbivorous and graniverous insects was highlighted by Cheplick \& Clay (1988), implying varying chemical defences as a function of environment, host, and microsymbiont genetics. Indeed, Ball et al. (1995) discovered that lolitrem B concentrations varied up to five fold and peramine up to sixfold among 17 perennial ryegrass plants from pastures, and that the variations were positively correlated with hyphal concentration of $N$. lolii. This suggests that environmental and host genotype effects on endophyte growth and metabolic activity within the plant are strong determinants of the alkaloid concentrations. In this case, genetic differences among endophytes could not be ruled out as contributors to phenotypic variation on alkaloid quantities. Spiering et al. (2005) demonstrated that lolitrem B, peramine, and ergovaline concentrations were weakly determined by fungal mass, but strongly associated with host tissue type and age and host genotype, in manners specific to each alkaloid.

The strong effect of host genetics on ergovaline production was illustrated by Latch (1994) by artificially infecting 19 ryegrass genotypes with the same endophyte strain, growing the plants in a controlled environment, and measuring a 10-fold variation in alkaloid concentration. In an effort to elucidate the genetic control of this range of ergovaline expressions, Easton et al. (2002) performed diallel crosses and progeny testing 
among 16 of the same plants. They found that ergovaline and peramine concentrations varied around five fold and were positively correlated, plus both were positively correlated with endophyte hyphal mass. High heritability estimates for alkaloid concentrations indicate the possibility of breeding for low levels of certain alkaloids through host control. Findings by Adcock et al. (1997) suggested the same possibility in tall fescue.

\section{Conclusions}

The wide and unpredictable range in phenotypic expression of Festuca and Lolium grasses as a function of endophyte presence and genotype has frustrated the efforts of ecologists to understand the biology and of agronomists to control the detriments and benefits of the symbioses. The fact that endophyte strains lacking a particular type of alkaloid in their wild hosts retain that profile in a new host indicates a qualitative effect of the endophyte on the host, at least for alkaloids. Tanaka et al. (2006) recently identified a key metabolic controller of host-endophyte mutualism in that a compatibly sustainable endophyte produces reactive oxygen species that prevent it from aggressive, parasitic growth in its natural host, whereas parasitic strains lack the ability to produce those oxidants in incompatible hosts. This finding may pave the way to further elucidation of mechanisms explaining variation in host-endophyte interactions. Results of growth, endophyte, and alkaloid analysis by Spiering et al. (2005) indicate complex orchestration of endophyte activity and fate of alkaloid transport by the host genotype, which probably explains the largely quantitative control that the host exerts over endophyte expression. Recent advances in gene discovery and transcriptome analysis offer opportunities to identify metabolic factors that explain key points of the plant-endophyte symbiosis (Spangenberg et al. 2005).

\section{ACKNOWLEDGEMENTS}

Support for the author's research by USDA-ARS Dale Bumpers Small Farm Research Center (Agreement no. 6227-21310-00721S) is gratefully acknowledged.

\section{REFERENCES}

Adcock, R.A.; Hill, H.S.; Bouton, J.H.; Boerma, H.R.; Ware, G.O. 1997. Symbiont regulation and reducing ergot alkaloid concentration by breeding endophyte-infected tall fescue. Journal of Chemical Ecology 23: 691-704.

Assuero, S.G.; Matthew, C.; Kemp, P.D.; Latch, G.C.M.; Barker, D.J.; Haslett, S.J. 2000. Morphological and physiological effects of water deficit and endophyte infection on contrasting tall fescue cultivars. New Zealand Journal of Agricultural Research 43: 49-61.

Ball, O.J-P.; Prestidge, R.A.; Sprosen, J.M. 1995. Interrelationships between Acremonium lolii, peramine, and lolitrem B in perennial ryegrass. Applied and Environmental Microbiology 61: 1527-1533.

Belesky, D.P.; Fedders, J.M. 1996. Does endophyte influence regrowth in tall fescue? Annals of Botany 78: 499-505.

Belesky, D.P.; Stringer, W.D., Hill, N.S. 1989. Influence of endophyte and water regime upon tall fescue accessions. I. Growth characteristics. Annals of Botany 63: 495-503.

Bouton, J.G.; Latch, G.C.M.; Hill, N.S.; Hoveland, C.S.; McCann, M.A.; Watson, R.H.; Parish, J.A.; Hawkins, L.L.; Thompson, F.N. 2002. Reinfection of tall fescue cultivars with non-ergot alkaloid producing endophytes. Agronomy Journal 93: 567-574.
Buck, G.W.; West, C.P.; Elbersen, H.W. 1997. Endophyte effect on drought tolerance in diverse Festuca species. pp. 141-143. In: Neotyphodium/grass interactions. Eds. Bacon, C.W.; Hill, N.S. Plenum Press, New York.

Bultman, T.L.; Conard, N.J. 1998. Effects of endophytic fungus, nutrient level, and plant damage on performance of fall armyworm (Lepidoptera: Noctuidae). Environmental Entomology 27: 631-635.

Cheplick, G.P. 1998. Genotypic variation in the regrowth of Lolium perenne following clipping: effects of nutrients and endophytic fungi. Functional Ecology 12: 176-184.

Cheplick, G.P. 2004. Recovery from drought stress in Lolium perenne (Poaceae): are fungal endophytes detrimental? American Journal of Botany 91: 1960-1968.

Cheplick, G.P.; Cho, R. 2003. Interactive effects of fungal endophyte infection and host genotype on growth and storage in Lolium perenne. New Phytologist 158: 183-191.

Cheplick, G.P.; Clay, K. 1988. Acquired chemical defenses of grasses: the role of fungal endophytes. Oikos 52: 309-318.

Cheplick, G.P.; Perera, A.; Koulouris, K. 2000. Effect of drought on the growth of Lolium perenne genotypes with and without fungal endophytes. Functional Ecology 14: 657-667.

Clay, K. 1987. Effects of fungal endophytes on the seed and seedling biology of Lolium perenne and Festuca arundinacea. Oecologia 73: 358-362.

Clay, K.; Schardl, C.L. 2002. Evolutionary origins and ecological consequences of endophyte symbiosis with grasses. The American Naturalist 160: s99-s127.

Easton, H.S.; Latch, G.C.M.; Tapper, B.A.; Ball, O.J-P. 2002. Ryegrass host genetic control of concentrations of endophytederived alkaloids. Crop Science 42: 51-57.

Eerens, J.P.J.; Lucas, R.J.; Easton, S.; White, J.G.H. 1998. Influence of the endophyte (Neotyphodium lolii) on morphology, physiology, and alkaloid synthesis of perennial ryegrass during high temperature, and water stress. New Zealand Journal of Agricultural Research 41: 219-226.

Eichenseer, H.; Dahlman, D.L. 1992. Antibiotic and deterrent qualities of endophyte-infected tall fescue to two aphid species (Homoptera: Aphidiae). Environmental Entomology 21: 1046-1051.

Faeth, S.H.; Helander, M.L.; Saikkonen, K.T. 2004. Asexual Neotyphodium endophytes in a native grass reduce competitive abilities. Ecology Letters 7: 304-313.

Fletcher, L.; Easton, S.; Popay, A.; Tapper, B.; Hume, D. 2006. Plant and endophyte genotype affects peramine concentrations in ryegrass/endophyte associations. pp. 93-96 In: Advances in Pasture Breeding. Grassland Research and Practice Series No. 12. New Zealand Grassland Association.

Hesse, U; Hahn, H.; Andreeva, K.; Förster, K.; Warnstorff, K; Schöberlein, W.; Diepenbrock, W. 2004. Investigations on the influence of Neotyphodium endophytes on plant growth and seed yield of Lolium perenne genotypes. Crop Science 44: 1689-1695.

Hesse, U.; Schöberlein, W.; Wittenmayer, L.; Förster, K.; Warnstorff, K; Diepenbrock, W.; Merbach, W. 2003. Effects of Neotyphodium endophytes on growth, reproduction and drought-stress tolerance of three Lolium perenne L. genotypes. Grass and Forage Science 58: 407-415.

Hill, N.S.; Stringer, W.C.; Rottinghaus, G.E.; Belesky, D.P.; Parrott, W.A.; Pope, D.D. 1990. Growth, morphological and chemical component responses of tall fescue to Acremonium coenophialum. Crop Science 30: 156-161.

Hunt, M.G.; Newman, J.A. 2005. Reduced herbivore resistance from a novel grass-endophyte association. Journal of Applied 
Ecology 42: 762-769.

Lewis, G.C. 2004. Effects of biotic and abiotic stress on the growth of three genotypes of Lolium perenne with and without infection by the fungal endophyte Neotyphodium lolii. Annals of Applied Biology 144: 53-63.

Latch, G.C.M. 1989. Plant improvement using endophytic fungi. pp. 345-346. Proceedings of the XVI International Grassland Congress, Nice, France. Association Francaise pour la Production Fourragere, Versailles, France.

Latch, G.C.M. 1994. Influence of Acremonium endophytes on perennial grass improvement. New Zealand Journal of Agricultural Research 37: 311-318.

Latch, G.C.M.; Hunt, W.F.; Musgrave, D.R. 1985. Endophytic fungi affect growth of perennial ryegrass. New Zealand Journal of Agricultural Research 28: 165-168.

Malinowski, D.; Belesky, D.P. 1999. Infection with Neotyphodium coenophialum-endophyte may affect the ability of tall fescue to use sparingly available phosphorus. Journal of Plant Nutrition 22: 835-853.

Malinowski, D.; Belesky, D.P. 2006. Ecological importance of Neotyphodium spp. grass endophytes in agroecosystems. Grassland Science 52: 1-14.

Marks, S.; Clay, K. 1996. Physiological responses of Festuca arundinacea to fungal endophyte infection. New Phytologist 133: 727-733.

Pennell, C.G.L.; Popay, A.J.; Ball, O. J-P.; Hume, D.E.; Baird, D.B. 2005. Occurrence and impact of pasture mealybug (Balanococcus poae) and root aphid (Aploneura lentisci) on ryegrass (Lolium spp.) with and without infection by Neotyphodium fungal endophytes. New Zealand Journal of Agricultural Research 48: 329-337.

Popay, A.J.; Bonos, S.A. 2005. Biotic responses in endophytic grasses. pp. 163-185. In: Neotyphodium in cool-season grasses. Eds. Roberts, C.A.; West, C.P.; Spiers, D.E. Blackwell Publishing, Ames, Iowa.

Popay, A.J.; Easton, H.S. 2006. Interaction between host plant genotype and Neotyphodium fungal endophytes affects insects. pp. 97-101 In: Advances in Pasture Breeding. Grassland Research and Practice Series No. 12. New Zealand Grassland Association.

Popay, A.J.; Hume, D.E.; Davis, K.L.; Tapper, B.A. 2003. Interactions between endophyte (Neotyphodium spp.) and ploidy in hybrid and perennial ryegrass cultivars and their effects on Argentine stem weevil (Listronotus bonariensis). New Zealand Journal of Agricultural Research 46: 311-319.

Popay, A.J.; Hume, D.E.; Mainland, R.A.; Saunders, C.J. 1995.
Field resistance to Argentine stem weevil (Listronotus bonariensis) in different ryegrass cultivars infected with an endophyte deficient in lolitrem B. New Zealand Journal of Agricultural Research 46: 519-528.

Richardson, M.D.; Hoveland, C.S.; Bacon, C.W. 1993. Photosynthesis and stomatal conductance of symbiotic and nonsymbiotic tall fescue. Crop Science 33: 145-149.

Saikonnen, K.; Lehtonen, P.; Helander, M.; Koricheva, J.; Faeth, S.H. 2006. Model systems in ecology: dissecting the endophytegrass literature. Trends in Plant Science 11: 428-433.

Spangenberg, G.C.; Felitti, S.A.; Shields, K.; Ramsperger, M.; Tian, P.; Ong, E.K.; Singh, D.; Logan, E.; Edwards, D. 2005. Gene discovery and microarray-based transcriptome analysis of the grass-endophyte association. pp. 103-121. In: Neotyphodium in cool-season grasses. Eds. Roberts, C.A.; West, C.P.; Spiers, D.E. Blackwell Publishing, Ames, Iowa.

Spiering, M.J.; Lane, G.A.; Christensen, M.J.; Schmid, J. 2005. Distribution of the fungal endophyte Neotyphodium lolii is not a major determinant of the distribution of fungal alkaloids in Lolium perenne plants. Phytochemistry 66: 195-202.

Tanaka, A.; Christensen, M.J.; Takemoto, D.; Park, P. Scott, B. 2006. Reactive oxygen species play a role in regulating a fungus-perennial ryegrass mutualistic interaction. The Plant Cell 18:1052-1066.

Timper, P.; Gates, R.N.; Bouton, J.H. 2005. Response of Pratylenchus spp. in tall fescue infected with different strains of the fungal endophyte Neotyphodium coenophialum. Nematology 7: 105-110.

West, C.P. 1994. Endophyte-infected grass physiology and drought tolerance. pp. 87-99. In: Biotechnology of endophytic fungi of grasses. Eds. Bacon, C.W.; White Jr., J.F. CRC Press, Inc., Boca Raton, Florida.

West, C.P.; Gwinn, K.D. 1993. Role of Acremonium in drought, pest, and disease tolerances of grasses. pp. 131140. In: Proceedings of the 2nd International Symposium on Acremonium/grass Interactions: plenary papers. Eds. Hume, D.E.; Latch, G.C.M.; Easton, H.S. AgResearch Grassland Research Centre, Palmerston North, New Zealand.

West, C.P.; Marlatt, M.L.; McConnell, M.E.; Piper, E.L.; Kring, T.J. 1998. Novel endophyte technology: selection of the fungus. pp. 105-115. In: Molecular and cellular techniques in forage improvement. Eds. Brummel, C.E.; Hill. N.S. Crop Science Society of America Special Publication no. 26. Madison, Wisconsin. 